\title{
Reflections on War
}

LISE HOGAN \& WILLIAM ANSELMI

\author{
FR A M N G W A R
}

We have conceived our intervention as a series of aphorisms that touch upon aspects not generally part of the discourse of/on war. In a sense, and however off the mark, Wittgenstein's family resemblances is our point of reference in terms of language usage when war surfaces as our common imaginary. The particular period we live in, the first days of a new millennium are historically determined as much as our interpretations are. With that in mind, the subversion of common emotive images into interpretable constructs must resist the attempt to rationalize the economization of the body. A way into the problematic is to show the ludic aspect of the discourses that gravitate around dying-for, and perhaps recuperate the art of dying as a natural response to war mongering.

\section{WAR AND VIDEO (GAMES)}

We have read that videogames are a training mechanism for would-be soldiers. Some might resent this and argue that the experience is not complete. Is the modern soldier the self-sufficient Alien, or the predatory mollusk looking for the empty shell, the secure refuge of another species the species of technological warfare? How does one mutate into a species? Or will the combat arena be ruled in the near future by the new American soldier as the ghost in the gun-slinging SWORDS (Special Weapons Observation Reconnaissance Detection Systems): the first armed robotic vehicles created for combat? The virtual disappearance of the human soldier from the real risk of personal "casualty"? (Or are these purely 
spectacular placebos?) After all, on seeing how burdened the s/ he soldier is while walking on the sands of time (Mesopotamia), one thinks of the weight of the equipment being carried. And the mind cannot fail to waver between omnipotent exterminator and the weak mollusk within the shell. The paradigm continuously shifts between Shiva and Bashful, the imperial mandate and innocence (innocence: ignorance with a smile). This continuous shift, the wavering spectrum, this haze over death, fog of the mind, is this the blissful state of the mystique of war? What of the body?

All senses are concentrated on the display at hand, through the shielding monitor of $s(t)$ imulated reality. But where are the markers of a successful kill, the decomposing bodies of the enemy soldiers? It is a clever travesty, this form of training, since one is no longer formed in response to the pungent odors and the fatigue and the heaviness of real combat but by moving and popping images, the delightful pleasure of a virtual game where enemies are simply "disappeared" off the screen. (And everyday language is consistently more militarized.) Yet a behavioristic lesson has been subliminally communicated: the act of "pulling the trigger" has now been rendered easy and habitual.

There has been a remarkable change from one century to the next; perhaps it is a paradigm shift, the marker of a new era, a renewed millennium. Passive pleasure - like many little deaths - takes the place of (re)productive work. Compassionately, it is anti-Protestant in its ethics. In order to salvage war's reputation as a character-building exercise for a nation, this can be said: war had to be infantilized. By a strange twist of fate, war manifests its parasitic nature by appropriating the mechanisms of social induction: play, game, finally, the ludic. Let us hope that it is only the socialization of war that is taking place, otherwise... If war for the next while is based on the ludic, how is the enemy to remain an enemy, and not a fellow player? After all, when I go online and play with unknown players, whose identity remains forever elusive, they can strategically switch from friend to foe with a flick of the wrist. How to justify that desperate need to totally eliminate the Other, when that Other is, like us, also a player? Are we moving towards a community of players, as immaterial as the ones on the Net? Perhaps enacting and advocating new forms of solidarity that will transcend nationality, loyalty to the cause, whatever the cause? This is a potentially subversive consequence that the sponsors of war have failed to foresee.

In nature, the she-wolf leads her young into the state of things by teaching them to smell out the prey, to stalk, to prey upon the weak, to cut off the blood supply (crush that artery) that kept the head of the target 
focused on the here and now. Once upon a time, the soldier manufacturers would train their recruits in an analogous fashion, if it were not the case that you were just thrown into a war by the state of things. But, you learned directly, you experienced in its totality the orgasmic brutality as a rush of adrenalin and the tediousness of the wait/weight as a depression in frozen time. Training by video-gaming divorces us from the nature of things, a dangerous dabbling with the powers of bored demiurges, divorced from the senses that (in)formed war before its transubstantiation into the image. Without technology (no technology can lay claim to any neutrality in the political arena), humanity could not go beyond its expectations, the glorious sound and fury, the shocking awe of the religious vision: the Passion of Man.

WAR AND HYGIENE

We have read of Futurism and we know the artists, although we preferred Palazzeschi to Marinetti. Nevertheless, the great writer of manifestos came up with one of the best-known dictums of the $20^{\text {th }}$ century: "Noi vogliamo glorificare la guerra, sola igene del mondo, il militarismo, il pattriottismo, il gesto distruttore dei libertari, le belle idee per cui si muore [...]" (We want to glorify war, sole hygiene of the world, militarism, patriotism, the destructive acts of anarchists, the beautiful ideas for which one dies).

If war is "the sole hygiene of the world," must we confer a detergent status, or better, a soap-y value to war? After all, it divides the world into good and evil like the inexorable soap-operatic storyline. This idea of a cleansing of the world is immediately contradictory - needless to say, the irrational was the Futurist's playing-field. If the Futurist meant to create scandal, to inflame souls, his dictum contradicts it, since what is removed in its becoming hygienic is the excess (the body-surplus) of the world. Yet, to remain faithful to Marinetti, it would have to be the whole species and not just its excess. There is only one way to accomplish such a feat - and it had to wait for an invention that the Futurists had only known in sound and in restricted image.

Television gossip and scandal sheets are replaced, for a brief moment of illumination that can be extended, leisurely, by recordings of bloodstained chronicles, by bloody fuming guts ( La Pelle (The Skin) by Liliana Cavani, 1981, indicates this state of things better than Coppola's Apocalypse Now). War, just like a soap opera, is presented in serial format with the addition of framing narratives, what's going to happen in the 
next episode, in the next match, stay tuned... War is the hygienic sport for the new millennium. But, as such it must be parceled out in installments (Céline docet), since it is not the overkill that affects the spectator, but rather, his/her steady diet of programming. There is something promiscuously moral about this state of things, something that smells like indulgence and incense, confessional, as much as saying that there are no war crimes, or crimes against humanity, since war is The Crime Against Humanity. Accepting war as part of our nature, our feeble bio-political constitution, is tantamount to marking Guantánamo as a special event (as Carnival narratives do for the medievalists amongst us). That is not the case, Guantánamo is exactly what war is: to go back to the beginning, illo tempore, to rewrite the whole Big Bang in simple terms: I/ enemy of mine. (The enemy of my enemy is my friend...?) By this process, "my enemies" disappear (desaparecidos de la noche oscura) or are re-formulated (as my ludic extension: I make them appear/disappear) at will, I am the unshy Shiva, I script bio-stories. Along these terms, war is profoundly hygienic since it constitutes the grammar of life-narratives: a traditional grammar at best that, pragmatically, is never a generative grammar.

For everything, the happy medium that Futurism foresaw: speed, (commercial) speed and destruction, the hygiene of a species that can suffer, like a fourteen year old, tendonitis of the thumb because of over 100 sms messages sent per day. The thumb, that great signifier of evolutionary progress: the speed of a species revolves around a minuscule digit. The thumb marks the evolution of the trigger-finger. Futurism lost its chance to celebrate it when Marinetti decided that /thumb/ was sound, not materiality or agent. Did Marinetti know English?

Is it, then, the case that man is renewed by washing in the blood of his Other, by marking the self with the blood of his kill as a primeval rite of passage, as if coming out of a bloody womb? Or do we suspect that Marinetti, no matter how revolutionary his intent, how provocative his beautiful phrases, was in reality embedded in Christian liturgy?

\section{WAR AND NATURE}

Is it not the case that any war is always a war against Nature? That the technology that develops from warring is actually the way by which we, as human beings, recede ourselves away from being in nature to being 'post' nature? After all, with each new weapon, with each development in our warfare technology, its accompanying language and neologisms, Nature is sidelined like an over-the-hill athlete. Smart bombs, for example, 
do not require a sunny sky to celebrate their existence; they are contingent on chips and sensors, on our extensions into the world. Geometry and, most important, gravity are washed out of our considerations when the little bomb we throw into the mist tumbles and falls back upwards to explode at a height of $1.50 \mathrm{~cm}$, making sure that bodies do not escape their manifest destiny. At this point, darkness, having being conquered as have the rest of the intermediaries that nature provides between warring bodies (re-constituted into an ethics of war, the code of behavior that dictated the fight between knights of lore), the only remaining disturbance to completion is the sun. The periodic sun-flares bring havoc to the telemetry of instant-war, disrupting messages and forfeiting instant wins as promised by those scratch-and-win tickets that sponsor each and every war. The last natural obstacle that need be conquered is obviously the sun. That orb of light has gone from reigning as our primal god to overshadowing the earth as our natural and final enemy - when shall we, as in a song by Pink Floyd, "set the controls for the heart of the sun"?

\section{WAR AND CONTROL}

War has crept into our everyday life on account of the power of the media. How it has remained in our imaginary and replaced basic humanistic tenets after centuries of development is a Miracle. And how the irrational has become an antagonizing religious system replete with its own economic mandate is a Revelation. Irrational incarnates, that's us, as we choke on a pretzel, or spread our joy abroad.

After the hippies, the flower children and their pagan rituals, where the ultimate sacrifice was the communal smoking of a joint, America regained its specious consciousness. An actor became president, consequently: war against crime, war against drugs, the enduring war against poverty (launched during Lyndon Johnson's Sixties administration). So typically Eighties, this form of indoctrination continues to be useful for our mirth-based "American way of life." It is just that, in every instance of our life-rhythms. The many different wars on civil society prepared the common mass for a totalizing and everlasting war. A war encoded in a competitive economy, they have generated a subliminal shift within social consciousness, so that the de-solidaritized practice means the refiguring of my neighbor into my potential enemy. Such a process is so akin to what Orwell had imagined that we must rejoice in this fact: someone is still reading books. 
An article recently circulated around the world: "Love bomb would set off sexual explosion," or at least this was the headline in some Englishlanguage papers that reported it from the Daily Telegraph. It mentions that in the 1990s several bombs were being developed by the U.S. Air Force Wright Laboratory in Dayton, Ohio. One particular bomb seems to indicate that, somehow, a merry prankster, a hippy, had burrowed his / her way all the way to the top. The "love bomb." A bomb that would sexually stimulate enemy troops and make them find each other irresistible can only be part of the Sixties' imaginary. This is freedom realized across genders - everyone make love, now! Since winds are incontrollable, it would mean that all soldiers, enemy and friendly, would join together in the great chain of being. An orgy instead of carnage, how succulently pagan, so much surplus re-released, so much love.

And, if that weren't enough, the merry prankster also introduced the idea of a stink bomb on a mass scale. Imagine, your comrade accusing you of reeking of halitosis, or of gratuitous flatulence. How simply revolutionary, how perfect a bomb that after love-making (that must be the right sequence, right? First love, then allegations...) would have all the soldiers engaged in comments about warped etiquette, rude behavior. This is Dear Abby on acid meets Bambi on mushrooms, but only in America, unfortunately. Yet, one cannot resist the words that keep popping up from the unconscious: imagine, imagine... Imagine if they started a war and nobody came?... Make Love, Not War. Amarcord. Je me souviens.

WAR AND IMAGES

War seems best consumed as spectacle. Of all human activities, war seems best rendered by television. Its unbearable closeness enchants us and plays with our desires. The promise of carnage offered by the mediatic image, that collage of cadavres exquis turns the viewer into a zombie, a compulsive consumer of still life. (The photographic death mask of Che Guevara began the pop culture trend in the dissemination of erotic fascination with the death-image. This process - image as the assertion of death - reaches its apex with the video-clip showing the corpses of Saddam Hussein's sons. Yet, in this setting the bodies must be aesthetically manipulated so that the passage from the American viewer to the Iraqi viewer marks the passage from butchery to aesthetic re-composition. In other words, the passage from pop culture to mass culture must take into 
account the different sensibilities of diverse audiences under the banner of image etiquette. In the American case, the news, in contrast to the film industry, which exhausts the many compositions of death, must be hygienic. Only in this case is death sanitized, and only for this audience. Of course, notwithstanding our mediatic spell, we can always switch channels and congratulate our narcissistic selves as the profits rise in our investment in death through the FTSE and the Dow Index.

Who can really remember a poem about WWI? Those who do still remember Ungaretti, or Apollinaire, or Owen are few and fading, for fewer still today read poetry. Ironically, the New York Times alone is said to have published over a thousand poems about WWI during that precise period. Still, we seldom remember these lyrical words about war. Echoes of a distant past, their meaning is lost to us in the apocalyptic deluge of the image-world. In fact, we have a hard time remembering words, period. Our brains have been trained by post-WWII technology to move promptly from image to image, in a relentless elaboration of that final image we must surely join. So accustomed have we become to that particular spell that we have turned the image into a sustainable fetish. Videodrome stands out as the movie that epitomizes this renewal: recall the moment when the screen is licked up by one of the protagonists. Isn't this the case where desire abolishes that illusory "fourth wall"? Licking off the aura of the image, isn't this the ultimate communion? Becoming one with nature is so passé; becoming one with technology (that is, becoming one with ourselves, since through techné we extend into the world) is the only illusory, integrating process that we are left to join. One day a poet will come who will say words to this effect: "the man is the child of the machine," and we'll know then that Terminator was not a metaphor, but a modus vivendi. In the meantime, after Bataille, after Sontag, we take refuge in the icon of the shipwreck. Let us recall Ovid's famous words, isn't it better to stay put at the edge of things, to safely watch the shipwreck from afar and reflect on its consequences? On the couch, as I am watched unseen as I watch, on that comfortable and secure ground of looped-surveillance, while my Other prostrates itself in its decomposition, I write about dying, I am interrupted by a commercial.

Of course, it would be a paradoxical paroxysm to witness one's death. We can recapitulate our Christianity by that last feverish dash out-ofourselves, where we end up sympathizing with the corpse in front of us, the dead body that has preceded us, and all thanks to an image. Wouldn't we forget all of this, the enormous possibility, if it were not for images? 
We remember images: a mushroom cloud, a lager, decomposing bodies that have lost any resemblance to anyone we knew, and that are now a visual omnibus of death. By virtue of serendipity a question arises: was television invented to show war? Are all television programs, past, present and future, derivative of war as a process? Television surpasses the photograph in the sense that it gives movement to what is caught in the frozen moment of death. The dynamic of death is made palpable; you can almost stretch your hand and reach out and touch a cadaver. But thanks to an impenetrable stage made of glass, that experience is left hanging, like the smoke of a cigarette. In this sense we have (for a second, experienced our worst nightmare,) passive-death. We do not have to smoke a cigarette to let the lungs do the breathing, and we do not have to feel the bloody corpse to recognize death. After all, death is the reflected image, the last image in the blink of an eye. As we move forward in time, as the glass stage is superseded by plasma flow (what does it taste like?), the transfusion of fear mediates our passing together, we internalize passive-death while under the spell, the final frontier of horror vacui: the empty gaze of the cadaver.

Given that the barrier between passive-death and represented-death can never be overcome, war as an image with everything it contains, the contents of the death-process, is integrated into the fabric of the familial and the familiar. We remember how Vietnam was part of the American supper experience. How the bottle of ketchup on the table reflected the color of parts of bodies - where Carnival met Halloween kaleidoscopically - in pools of blood. In this sense, death becomes us, and is in the abrupt rendition of an analogy ingested and then wasted, flushed away so that the experience can be renewed as an ongoing ritual.

War as image(s) - better than any videotaped accident, from the crushing, exploding airplane, to the motorcycle stunt gone bad - is how the mastering of our physical finality takes place. Perhaps, we have moved from war to war ever since the advent of television, be it a tragic rendition or a comic performance, from the documentary to $M^{*} A^{*} S^{*} H$. For there is always someone who possesses history, the success of certain procedures (history as the spirit of the entrepreneur). In the age of stasis, repetition (the only possible dynamic) is already the "Spirit of America," the planned sitcom about the making of a Western-style television network in contemporary Baghdad. From $\mathrm{M}^{*} \mathrm{~A}^{*} \mathrm{~S}^{*} \mathrm{H}$ to the "Spirit of America," from parody to isomorphism. Reality is war, war is image, reality is image syllogistic TV. 